\title{
Jaw Fractures: Managing the Whole Patient
}

\section{Emeka Danielson Odai*}

Department of Oral and Maxillofacial Surgery, Ejide Dental Complex, University of Benin Teaching Hospital, Nigeria

The mandible and maxilla constitute the jaws and are the bony structures in which the teeth are set to form the framework of the mouth, contributing the lower third and part of the middle third of the facial skeleton respectively. Fractures of these bony structures are a component of the spectrum of "maxillofacial fractures" and vary in severity from simple crack in the alveolus to a major disruption of the entire maxillofacial skeleton [1-3].

Motor vehicle accidents (MVA) and assaults are major causes of facial fractures worldwide. Other causes include work-related falls, sporting injuries, industrial trauma, gunshot wounds, animal bites and domestic accidents. Geographical locations, social trends, alcohol and drug abuse, road traffic legislation and seasons are the various factors of relative importance affecting the epidemiology of maxillofacial bone fractures. Available evidence show male preponderance, with highest incidence in the third decade of life $[4,5]$.

The clinical findings in jaw fractures include pain, swelling, facial disfigurement, bleeding, deviation of the lower third of the face, limited mouth opening, deranged occlusion, sublingual hematoma, crepitus, gagging of occlusion, step deformity and possible long-term consequences in the maxilla. The initial evaluation of the injured patient should be geared towards the identification of life threatening injuries: injuries to the chest, abdomen and major vessels may require emergency treatment and takes precedence over maxillofacial injuries. The multiple-injured patient may be hemodynamically unstable and in such a case, the maxillofacial surgeon should work in tandem with the orthopedic and trauma surgeons, to stabilize and treat the patient. It is pertinent that the patient is not mobilized until appropriate support of the cervical spine has been undertaken, to prevent further injury [6,7].

The occurrence and treatment of jaw fractures have consequences including loss of man hours and adverse effects on the functional and psychological aspects of life. This is associated with an enormous financial, social, psychological and physical burden; and negatively impacting on social functionality, employability, honesty and trustworthiness. It is pertinent therefore to keep these in perspective, when treating a patient with jaw trauma. The patients should be reminded that their quality of life may be altered to varying extents. Patients with significant maxillofacial fractures, neurologic deficit and soft tissue damages with the subsequent financial burden of treatment, among other variables will certainly experience a change in the quality of life [7-12].

The protocol for definitive management of jaw fractures, over the years, has involved the use of stainless steel wiring, arch bars, external pin fixation and titanium plates and screws among others. Providing a range of fixation from non-rigid to rigid internal fixation. When properly employed, the use of titanium plates and screw systems is excellent in biomechanical and biocompatibility parameters, and allows immediate or early restorations of functions. This notwithstanding, the use of titanium plates and screws is still not so widely practiced in most developing economies, because they are not readily available and in centers where they are available, they are very expensive [3-7].

Treatment outcome measures have changed dramatically with the World Health Organization's broadened concept of health to mean "a state of complete physical, mental and social well-being, and not merely the absence of disease"; with clinicians and medical researchers diverting their interest to patient-reported outcomes (PRO) or secondary outcome measures. This becomes important endpoints in comparative effectiveness research and in patient-centered health care delivery. Assessment of secondary outcome measures can be problematic; it is largely subjective, hence appropriately scaled and reliable instruments, with content, criterion-related and construct validity have been developed to scientifically measure the secondary or patient reported outcome measures. Among these are the World Health Organisation Quality of Life (WHOQoL)-BREF and the Hospital Anxiety and Depression Scales (HADS).

Whatever the state of economy, available skill and facilities, all efforts should be geared towards treating the 'whole' patient with jaw fractures-body and mind! Available evidence has proven the all methods of treatment can efficiently take care of the body. And the controversies ${ }^{13}$ on forms of treatment to be adopted for jaws fractures should be put to rest as it has been proven that the only rigid internal fixation significantly heals the afflicted's body and mind to significant extent [3].

Finally, the use of the plate system for rigid internal fixation should be the treatment protocol of choice in patients with jaw fractures, as it significantly improves the HRQoL during convalescence; there is need for involvement of mental health experts in management of jaw fracture patients to address the psychological burden this put in parenthesis appropriately as [13].

\section{References}

1. Charles Brunicardi F (2005) Schwartz's Principle of Surgery (8thedn) shock publications, Japan. 23: 1680-1808

2. Miloro M (2004) Peterson's principles of oral and maxillofacial surgery (2ndedn) Hamilton, London, 327-444

3. Odai ED (2015) Evaluation of treatment outcome and health-related quality of life (HRQoL) in jaw fracture patients seen and treated with rigid and semi-rigid osteosynthesis: a prospective comparative study. Dissertation presented to the National Postgraduate Medical College of Nigeria, in partial fulfillment of the requirements for the award of fellowship of the college in the specialty of oral and maxillofacial surgery.

4. Ugboko VI, Odusanya SA, Fagade OO (1998) Maxillofacial fractures in a semiurban Nigerian teaching hospital. A review of 442 cases. Int J Oral Maxillofac Surg 27: 286-289.

5. Banks P, Brown A (2001) Fractures of the facial skeleton (1stedn), Wright, Oxford publications, USA. 1-155.

6. Adeyemi MF (2009) Clinical evaluation of early release of maxilla-mandibular

*Corresponding author: Emeka Danielson Odai, Professor, Department of Ora and Maxillofacial Surgery, Ejide Dental Complex, University of Benin Teaching Hospital, Ugbowo, Benin City, Nigeria, Tel:+234-803-383-7479; E-mail: danielson.odai@uniben.edu

Received: October 27, 2015; Accepted: November 05, 2015; Published: November 15,2015

Citation: Odai ED (2015) Jaw Fractures: Managing the Whole Patient. Ora health case $\operatorname{Rep} 1: \mathrm{e} 104$. doi:10.4172/2471-8726.1000e104

Copyright: (C) 2015 Odai ED. This is an open-access article distributed under the terms of the Creative Commons Attribution License, which permits unrestricted use, distribution, and reproduction in any medium, provided the original author and source are credited. 
fixation in the management of mandibular tooth bearing region. Dissertation submitted to the National Postgraduate Medical College of Nigeria in partial fulfilment of the requirements for the awards of fellowship of the college 1-62.

7. Obuekwe ON, Ojo MA, Akpata O, Etetafia M (2003) Maxillofacial trauma due to road traffic accidents in Benin City, Nigeria: a prospective study. Ann Afri Med 2: 58-63.

8. Akinwande JA (1990) Fracture of the mandible due to road traffic accidents in Lagos, Nigeria. Nig Dent J 9: 15-22.

9. Bisson JI, Shepherd JP, Dhutia M (1997) Concept of Oral-health, disease and quality of life. J Trauma-Injury Inf \& Crit Care 43: 496-500.
10. Perry M (2009) Maxillofacial trauma-developments, innovations and consequences. Inj. 40: 1252-1259.

11. Osoba D (2007) Translating the science of patient-reported outcomes assessment into clinical practice. J Natl Cancer Inst 5-11.

12. Ukpong DI, Ugboko VI, Ndukwe KC, Gbolahan OO (2008) Health-related quality of life in Nigerian patients with facial trauma and controls: a preliminary survey. Br J Oral \& Maxillofac Surg 46: 297-300.

13. Andreasen JO, Storgård JS, Kofod T, Schwartz O, Hillerup S, et al. (2008) Open or closed repositioning of mandibular fracture: is there a difference in healing outcome? A systematic review. Dent Traumatol 24: 17-21. 